\title{
ERGEBNISSE DER EXAKTEN NATURWISSENSCHAFTEN
}

\author{
HERAUSGEGEBEN VON DER
}

SCHRIFTLEITUNG DER *NATURWISSENSCHAFTEN *

\section{ERSTER BAND}

MIT 35 ABBILDUNGEN

\author{
BERLIN \\ VERLAG VON JULIUS SPRINGER \\ 1922
}

